\title{
A hybrid district heating substation with an adsorption chiller and PCM storage units: a concept and preliminary study
}

\author{
Arkadiusz Szczęśniak ${ }^{1 *}$, Wojciech Bujalski ${ }^{2}$, Andrzej Grzebielec ${ }^{3}$, Kamil Futyma ${ }^{4}$, Jarosław Karwacki $^{5}$ and \\ Paulina Rolka ${ }^{6}$ \\ ${ }^{1}$ Institute of Heat Engineering, Warsaw University of Technology, Warsaw, Poland \\ ${ }^{2}$ Institute of Heat Engineering, Warsaw University of Technology, Warsaw, Poland \\ ${ }^{3}$ Institute of Heat Engineering, Warsaw University of Technology, Warsaw, Poland \\ ${ }^{4}$ Institute of Heat Engineering, Warsaw University of Technology, Warsaw, Poland \\ ${ }^{5}$ The Szewalski Institute of fluid-flow machinery Polish Academy of Sciences, Gdansk, Poland \\ ${ }^{6}$ The Szewalski Institute of fluid-flow machinery Polish Academy of Sciences, Gdansk, Poland
}

\begin{abstract}
Development of the district heating system (DHS) is needed to achieve the Renewable Energy Directive goals. To maintain the economic profitability of DHN, the increase of intensity of heat production/consumption has to be ensured. Well, a known method is a cold production using an adsorption heat pump. However, developing a system suitable for implementation in the district heating companies is very difficult. As a solution, the authors propose a composite substation equipped with the adsorption heat pump and the heat/cold storage system based on a PCM.
\end{abstract}

\section{Introduction}

One of the possible ways to meet the targets specified in the Renewable Energy Directive [1] is the widespread use of district heating systems (DHSs), and recently many improvements of the technology have been reported $[2,3]$.

A typical profile of district heat demand in Poland is characterized by a huge ratio of winter to summer heat consumption (10:1) [4]. The exemplary profile of heat consumption in Poland is shown in Fig. 1.

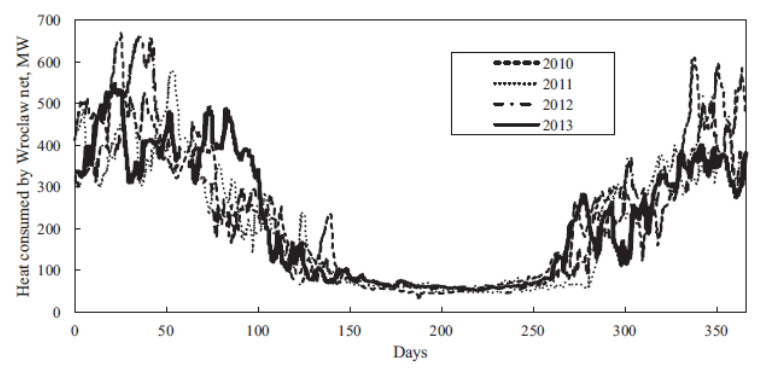

Fig. 1. Yearly profile of heat consumption in a middle-sized Polish city, by Chorowski [4]

A similar phenomenon is also observed in other European countries, e.g., researchers in the Netherlands [6] and Finland [7] report very similar heat demand profiles. The phenomenon makes the profitability of district heating systems questionable [5] and drives research towards increasing heat consumption during the summer period.
The main focus of research is the integration of cooling systems with adsorption chillers driven by district heat - such concepts are reported in the literature as the next $\left(5^{\text {th }}\right)$ generation of district heating systems [8][9].

A number of studies have investigated the concept of conversion of low-temperature heat into cold. The idea of thermal cooling with adsorption chillers was described by Ingo Daßller et al. [10], where ACS08, 8 $\mathrm{kW}$ chiller was used for cooling workshop studio in Austria. The experience gained by the Authors revealed the system is a promising alternative to conventional cooling systems, but the minimum temperature of the heat source should be $<80^{\circ} \mathrm{C}$.

The concept of the use of adsorption refrigeration units driven by heat from district heating systems instead of electrically driven chillers was scrutinized by Grzebielec et al. [11]. The authors concluded the integration of heat pumps with district heating systems seems to be a perspective solution as it enables to use of existing infrastructure for cold generation at the customer side - there is no need for cold transmission for long distances. The typical water temperature during the summer period is within the range of $50^{\circ} \mathrm{C} . .70^{\circ} \mathrm{C}$. Although the minimum required temperature of the heat source is $50^{\circ} \mathrm{C}$, this temperature does not ensure efficient operation of the refrigeration unit. Thus Authors concluded the solution is uneconomic due to the low COP - at 0.14 with the relatively high district heating water prices.

Chorowski et al. [4] studied possible options for cooling buildings by adsorption chillers driven by

\footnotetext{
*Corresponding author: arkadiusz.szczesniak@pw.edu.pl
} 
district heating heat. The analysis was based on the reference object with a maximum heat load of $100 \mathrm{~kW}$ for ambient temperature $35^{\circ} \mathrm{C}$ and a minimum of $0 \mathrm{~kW}$ below $17^{\circ} \mathrm{C}$. Authors report that the adsorption chillers for applications as stand-alone commercial airconditioning systems are not satisfactory due to control characteristics, big-time constants, and investment cost. To enable efficient conversion of low-temperature heat into cold during the summer, the Authors propose a hybrid air-conditioning system consisting of adsorption and compressor chiller. The reported investigation revealed the possibility of using 0.5 to $0.9 \mathrm{TJ}$ of extra district heating heat per year. The value depends on the system configuration. However, the adsorption share in the cold production should not exceed $50 \%$.

McNally et al. [12] experimentally investigated the performance of an adsorption chiller operation in two modes:

- A constant hot water temperature - to represent the district heating system

- A varying hot water temperature - to represent the heat from flat plate solar collectors.

The experiment shows the temperature variations of hot water have a greater effect on performance than the flow variations. Therefore adsorption chillers are suitable for operation with district heating systems.

The challenging issue limiting the integration of adsorption chiller for cold generation is the low heating medium's temperature for commercial adsorption heat pumps. The upgrade of the substation by thermal storage tanks with renewables could raise the available heat source temperature [15]. PCM storage unit seems promising among various heat storage technology as it requires $40 \%$ less volume than the water-based heat accumulator [13]. The use of PCM heat storage is not deeply recognized as very limited information is reported [14]. The influence of using heat storage with PCM on inlet and outlet temperatures in substations was investigated by Nogaj et al. [15]. The authors examined the integration of PCM with a single-function substation whose thermal power is $150 \mathrm{~kW}$. After applying the $\mathrm{PCM}$, the difference in average return water temperature was reduced from $7.15 \mathrm{~K}$ to a value of $2.29 \mathrm{~K}$. This allowed the accumulation of $69.5 \%$ of excess heat and improved the efficiency of the entire heating system by $22 \%$. The authors concluded the use of PCM accumulators gives the potential energy saving up to $6.7 \%$.

\subsection{Novelty}

The adsorption chillers seem to be a perspective technology in district heating systems; however, their development is limited by the temperature of the heat source that does not ensure efficient operation.

The paper introduces a novel concept of a hybrid substation integrated with a PCM and adsorption heat pump. The PCM-based storage facility's main aim is to increase the available cooling power during the summer period. Currently, water temperature during the summer is ca $65^{\circ} \mathrm{C}$; thus, the adsorption cooling units are able to operate with an efficiency ca $0.3-0.45$. The storage of cold enables the development of cooling systems with three times bigger cooling power than the limits imposed by technical possibilities of the heat district system.

\section{Theory}

The substation is a key element of the district heating system, which is responsible for transferring heat from a medium that circulates in the DHS to the internal heating system inside buildings. Currently, the use of heat during the summer period is very low. The integration of the cooling loop for the district heating system would increase the intensity of heat consumption during the summer as it will be used for cold generation by the adsorption heat pumps.

\subsection{The hybrid substation}

The concept of integration of an adsorption heat pump with a substation is shown in Figure 1. The substation contains a heating loop - a regular heat exchanger for heating purposes and a cooling loop - a modified loop, which the paper introduces.

The cooling loop is split into two sub loops (I) hot circuit, (II) cold circuit. The hot circuit comprises (2) DHS heat exchangers for driving (7) an adsorption heat pump. Additionally, the hot circuit is supported by the (5) PV panels and (6) PCM storage unit.

The heat pump provides cold for the building. In the second part of the cooling loop, the PCM (8) is integrated for the cold storage, which covers 2 or 3 times greater demand than the demand resulting from the limitations imposed by the infrastructure.

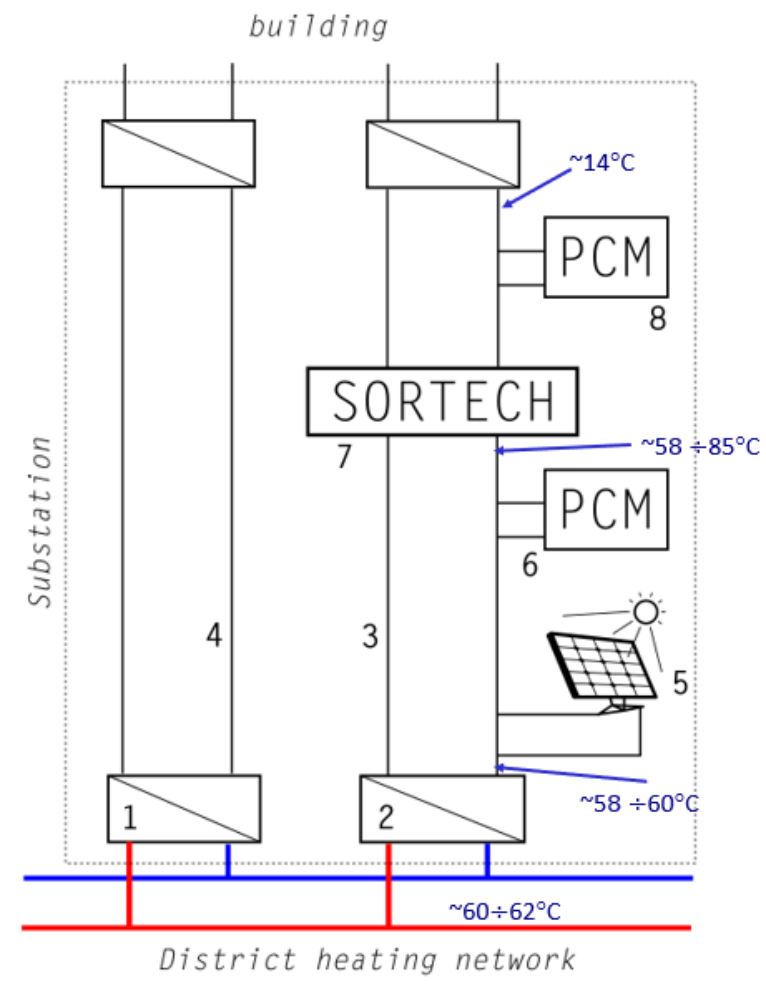

Fig. 2. Simplified scheme of the composite substation 


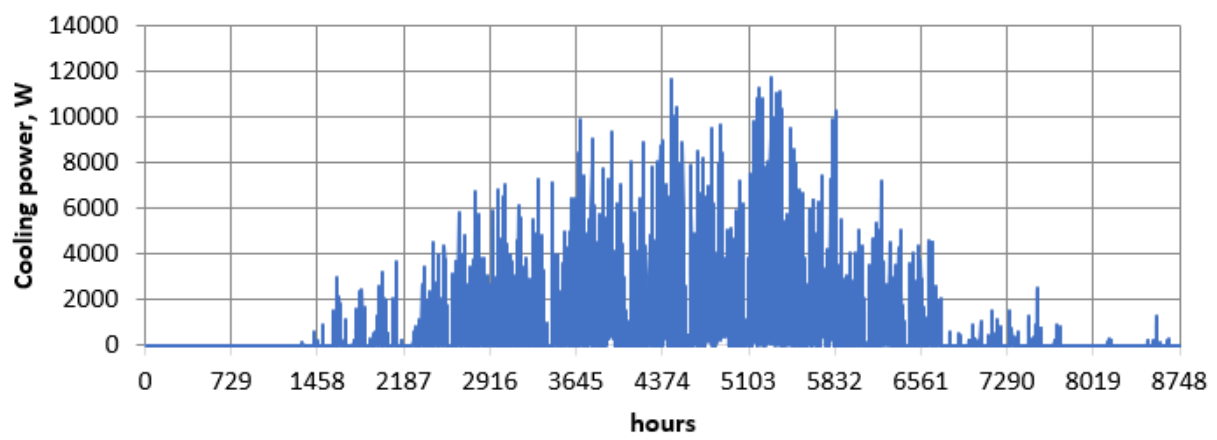

Fig. 3. Simplified scheme of the composite substation

As the heating substation will be integrated with an easter-type district heating system, the expected temperature in the network during the summer period will be approximately $60 . .62^{\circ} \mathrm{C}$, and the presence of PV panels enables to raise the temperature up to $85^{\circ} \mathrm{C}$. The difference between temperature increase due to PV panels and demand will be equalized by PCM at the side of the hot loop and cold loop.

\subsubsection{Basic technical data}

The hybrid substation is integrated with the district heating system in a small city in northeastern Poland. The district heating system consists of one heat source, a district heating network, and substations.

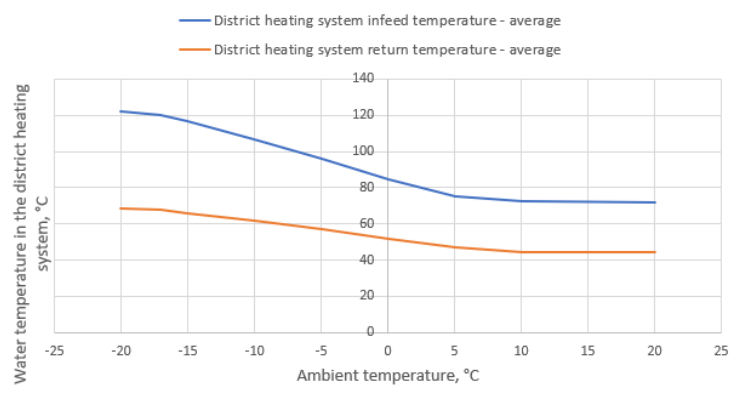

Fig. 4 Annual heat load duration curve

The district heating system operates with varying water flow rates and supply temperatures. The design operating temperature is $120 / 65^{\circ} \mathrm{C}$, which corresponds to ambient temperature $-20^{\circ} \mathrm{C}$. The temperature variations with respect to ambient temperature are shown in Fig. 4. During the summer period, the heating medium is $65^{\circ} \mathrm{C}$, and the return water is $50^{\circ} \mathrm{C}$. The heating medium is water whose pressure is $0.9 \mathrm{MPa}$ and $0.2 \mathrm{MPa}$ during winter and summer, respectively.

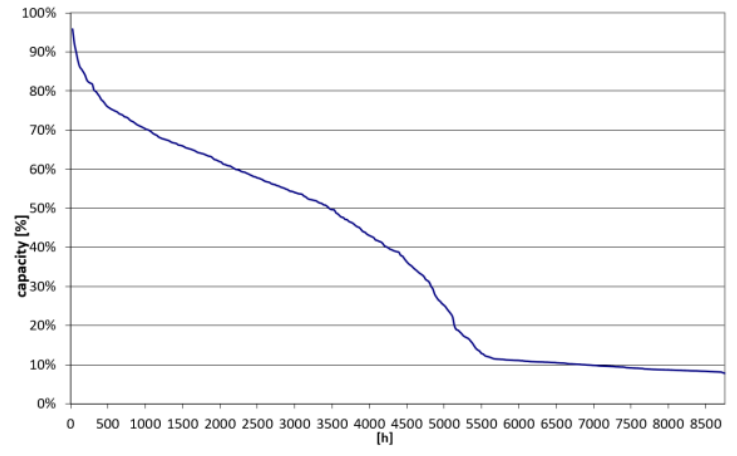

Fig. 5 Annual heat load duration curve

The district heating system's annual heat load duration curve, where the heating substation is installed, is shown in Fig. 5. It is observed that the heat demand during the summer period is ca. $10 \%$ of the maximum heat demand. Therefore, there is a potential to increase heat consumption during the summer without modifying the existing infrastructure.

The substation is converted into a hybrid substation according to the scheme shown in Fig. 2. The substation delivers heat for the office building. The basic technical data of the building are listed in Table 1 .

The prediction of detailed cooling power for the office building is shown in Fig 2. The demand for cooling is due to the need to maintain indoor thermal comfort, i.e., the temperature should be lowered to $+25^{\circ} \mathrm{C}$ during summer.

The basic technical data of the adsorption heat pump - SORTECH, eCoo 2.0 are presented in Table 2.

Table 1. Technical data of the adsorption heat pump

\begin{tabular}{|c|c|}
\hline Parameter & Value \\
\hline Bulding area & $142 \mathrm{~m}^{2}$ \\
\hline Volume & $426 \mathrm{~m}^{3}$ \\
\hline Amount of rooms & 6 \\
\hline Room heights & $3 \mathrm{~m}$ \\
\hline
\end{tabular}


Table 2. Technical data of the adsorption heat pump

\begin{tabular}{|c|c|}
\hline Parameter & Value \\
\hline Cooling power & $16 \mathrm{~kW}$ \\
\hline Heating power & $50 \mathrm{~kW}$ \\
\hline COP & $0.65 \mathrm{~kW}$ \\
\hline $\begin{array}{c}\text { The temperature of hot } \\
\text { water }\end{array}$ & $50 . .95^{\circ} \mathrm{C}$ \\
\hline $\begin{array}{c}\text { Recooling water } \\
\text { temperature }\end{array}$ & $22 . .40^{\circ} \mathrm{C}$ \\
\hline $\begin{array}{c}\text { Cooling water temperature } \\
\text { tem }\end{array}$ & $81^{\circ} \mathrm{C}$ \\
\hline
\end{tabular}

The expected operating parameters of the adsorption heat pump during the summer period are listed in Table 3. Based on the regulatory table, the analysis of heat pump operation was based on various temperatures: $58^{\circ} \mathrm{C}, 60^{\circ} \mathrm{C}$, and $63^{\circ} \mathrm{C}$.

Table 3. Operational data

\begin{tabular}{|c|c|c|c|}
\hline $\begin{array}{c}\text { Hot water } \\
\text { temperature }\end{array}$ & $\mathbf{5 8}^{\circ} \mathbf{C}$ & $\mathbf{6 0}^{\circ} \mathbf{C}$ & $\mathbf{6 3}^{\circ} \mathbf{C}$ \\
\hline $\begin{array}{c}\text { Recooling } \\
\text { water } \\
\text { temperature }\end{array}$ & $27^{\circ} \mathrm{C}$ & $27^{\circ} \mathrm{C}$ & $27^{\circ} \mathrm{C}$ \\
\hline $\begin{array}{c}\text { Cold water } \\
\text { temperature }\end{array}$ & $14^{\circ} \mathrm{C}$ & $14^{\circ} \mathrm{C}$ & $14^{\circ} \mathrm{C}$ \\
\hline $\begin{array}{c}\text { Input thermal } \\
\text { power }\end{array}$ & $12.4 \mathrm{~kW}$ & $13.4 \mathrm{~kW}$ & $14.9 \mathrm{~kW}$ \\
\hline $\begin{array}{c}\text { Hot water } \\
\text { inlet }\end{array}$ & $58^{\circ} \mathrm{C}$ & $60^{\circ} \mathrm{C}$ & $63^{\circ} \mathrm{C}$ \\
\hline $\begin{array}{c}\text { Hot water } \\
\text { outlet }\end{array}$ & $53.7^{\circ} \mathrm{C}$ & $55.4^{\circ} \mathrm{C}$ & $57.9^{\circ} \mathrm{C}$ \\
\hline \begin{tabular}{c} 
Volume flow \\
\hline $\begin{array}{c}\text { Cooling } \\
\text { capacity }\end{array}$
\end{tabular} $2500 \mathrm{l} / \mathrm{h}$ & $2500 \mathrm{l} / \mathrm{h}$ & $2500 \mathrm{l} / \mathrm{h}$ \\
\hline $\begin{array}{c}\text { Cold water } \\
\text { inlet }\end{array}$ & $15.8^{\circ} \mathrm{C}$ & $16^{\circ} \mathrm{C}$ & $16.3^{\circ} \mathrm{C}$ \\
\hline $\begin{array}{c}\text { Cold water } \\
\text { outlet }\end{array}$ & $14^{\circ} \mathrm{C}$ & $6.7 \mathrm{~kW}$ & $7.6 \mathrm{~kW}$ \\
\hline \begin{tabular}{c} 
Volume flow \\
\hline${ }^{\circ} \mathrm{C}$
\end{tabular} & $2900 \mathrm{l} / \mathrm{h}$ & $2900 \mathrm{l} / \mathrm{h}$ & $2900 \mathrm{l} / \mathrm{h}$ \\
\hline${ }^{\circ} \mathrm{C}$ \\
\hline
\end{tabular}

\section{Discussion and conclusions}

The integration of adsorption heat pump with district heating system enables the increase of intensity of summer heat consumption. The main challenging issue lies in the temperature of the heat source - temperature available in the district heating system during the summer period (ca. $60^{\circ} \mathrm{C}$ ).

As the solution for too low available heat source temperature, we propose to increase the available temperature by system integration with two extra components:

1. PV panels for increasing the temperature in the hot loop,

2. PCM storage at hot and cold loops for equalizing heat/cold supply.

PCM storage units should prevent increased water flow through the substations as the heat could be stored in times of decreased demand and used in peak hours. Therefore, the paper's idea is to develop a substation that will increase heat consumption during the summer without significant changes in the district heating system operation.

The preliminary study revealed that the composite substation is a perspective solution that could increase heat consumption during the summer. It should result in the increased profitability of district heating systems. However, a more detailed study is required to optimize PCM storage tanks and control strategy selection. Our further work will focus on a detailed simulation of the proposed concept and model validation with the system operating data.

\section{Acknowledgments}

This work was financially supported by the National Research and Development Center in Poland in the framework of the POIR.04.01.04-00-0100/17-00 research project "Innovative heat and cold storage with PCM, operating in a modern installation intended to generate system heat", project acronym: Innostorage.

\section{References}

1. European_Union, Off. J. Eur. Union (n.d.)

2. H. Lund, P. A. Østergaard, M. Chang, S. Werner, S. Svendsen, P. Sorknæs, J. E. Thorsen, F. Hvelplund, B. O. G. Mortensen, B. V. Mathiesen, C. Bojesen, N. Duic, X. Zhang, and B. Möller, Energy 164, 147 (2018)

3. A. R. Mazhar, S. Liu, and A. Shukla, Renew. Sustain. Energy Rev. 96, 420 (2018)

4. M. Chorowski, Z. Rogala, P. P. journal of refrigeration, and undefined 2016, Elsevier (n.d.)

5. M. Turski, K. Nogaj, and R. Sekret, Energy 187, 115885 (2019)

6. A. De Geus, H. De Beijer, and L. Krosse, in Energy Procedia (Elsevier Ltd, 2015), pp. 2331

7. M. Rämä and S. Mohammadi, Energy 137, 649 (2017)

8. S. Buffa, M. Cozzini, M. D’Antoni, M. Baratieri, and R. Fedrizzi, Renew. Sustain. Energy Rev. 104, 504 (2019)

9. S. Buffa, A. Soppelsa, M. Pipiciello, G. Henze, 
and R. Fedrizzi, Energies 13, 4339 (2020)

10. (n.d.)

11. A. Grzebielec, A. Rusowicz, M. Jaworski, and R. Laskowski, Arch. Thermodyn. 36, 15 (2015)

12. J. McNally, C. Baldwin, and C. A.

Cruickshank, in ASME Int. Mech. Eng. Congr.

Expo. Proc. (American Society of Mechanical Engineers (ASME), 2018)

13. B. Xu, P. Li, C. Chan, and E. Tumilowicz, Appl. Energy 140, 256 (2015)

14. D. Zhou, C. Y. Zhao, and Y. Tian, Appl. Energy 92, 593 (2012)

15. K. Nogaj, M. Turski, and R. Sekret, MATEC Web Conf. 174, 01002 (2018) 